\title{
Phosphine-Catalyzed $\beta^{\prime}$-Umpolung Addition of Nucleophiles to Activated $\alpha$-Alkyl Allenes
}

\author{
Tioga J. Martin, Venus G. Vakhshori, Yang S. Tran, and Ohyun Kwon \\ Department of Chemistry and Biochemistry, University of California, Los Angeles, 607 Charles E. \\ Young Drive East, Los Angeles, California 90095-1569
}

\begin{abstract}
$\mathrm{NuH}+$<smiles>[R]CC(F)=CC=[Pt]</smiles>

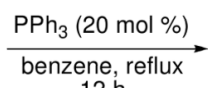

12

$\mathrm{NuH}=\mathrm{ROH}, \mathrm{RR} ' \mathrm{NH}, \mathrm{CH}_{2}(\mathrm{CN})_{2}, \mathrm{RCH}(\mathrm{CN}) \mathrm{CO}_{2} \mathrm{Et}, \mathrm{PhSH}$

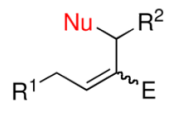

$42-99 \%$ yield

$\mathrm{R}^{1}=\mathrm{H}, \mathrm{Me} ; \mathrm{R}^{2}=\mathrm{H}, \mathrm{Ph}$, 4-pentenyl, $\mathrm{CO}_{2} \mathrm{Et} ; \mathrm{E}=\mathrm{CO}_{2} \mathrm{Et}, \mathrm{CN}$

Highly functionalized alkenes can be prepared through phosphine-catalyzed $\beta^{\prime}$-umpolung additions of nucleophiles (carbon-, oxygen-, nitrogen-, and sulfur-centered) to activated $\alpha$ disubstituted allenes, providing many potentially useful synthetic intermediates in good to excellent yields, often with high levels of stereoselectivity for the product olefin geometry. Various substitution patterns around the allene are compatible with the process, showcasing the synthetic utility of allenes under the conditions of nucleophilic phosphine catalysis.
\end{abstract}

Nucleophilic phosphine catalysis is firmly established as a reliable platform for a variety of transformations involving activated allenes as starting materials. ${ }^{1}$ Within this field, $\gamma$ umpolung addition of nucleophiles to activated allenes and acetylenes allows the formation of a myriad of substrates. Since the first report by Trost, ${ }^{2}$ there has been increasing interest in phosphine-catalyzed $\gamma$-umpolung additions of pronucleophiles to electron-deficient alkynes and allenes (Scheme 1; eq 1). ${ }^{3}$ Combining the mechanistic insights gained from studies of the $\gamma$-umpolung additions and nucleophilic phosphine-catalyzed reactions of $\alpha$ substituted allenoates developed in our laboratory ${ }^{4}$ and by others, ${ }^{5}$ we envisaged the possibility of a $\beta^{\prime}$-umpolung addition to $\alpha$-alkyl allenoates (Scheme 1; eq 2). This process facilitates functionalization of the seemingly unactivated $\beta^{\prime}-\mathrm{C}-\mathrm{H}$ bond, allowing the generation of unique, highly versatile olefinic products. The observed activation of the $\beta^{\prime}-$ carbon atom of $\alpha$-alkyl allenoates stems from the equilibrium between the $\beta$-phosphonium dienolate and the vinylogous ylide (see the mechanistic discussion below). ${ }^{4 \mathrm{~d}, \mathrm{f}, \mathrm{g}}$

We began our studies by treating ethyl $\alpha$-methyl allenoate with a variety of substituted phenols and catalytic $\mathrm{PPh}_{3}$ in benzene under reflux (Table 1). The reaction with phenol proceeded smoothly to produce the $\beta^{\prime}$-umpolung adduct 1a in quantitative yield as a single geometrical isomer (entry 1 ). To our delight, we detected no $\gamma$-umpolung addition product. Notably, unlike the requirements of the $\gamma$-umpolung addition, no basic or acidic/basic additives were needed for the $\beta^{\prime}$-umpolung reaction, ${ }^{2,3}$ which provided an expedient route to the allylphenyl ether 1a, a known intermediate in the functionalized coumarin synthesis. ${ }^{6}$ We also obtained high yields from reactions of phenols bearing electron-donating methyl or

ohyun@chem.ucla.edu .

Supporting Information Available Experimental procedures and characterization data for new compounds (PDF). This information is available free of charge via the Internet at http://pubs.acs.org. 
methoxy substituents (entries 2 and 3). The allylaryl ethers $\mathbf{1 d}-\mathbf{1 h}$ derived from phenols with electron-withdrawing substituents were, however, isolated in diminished yields (entries 4-8), the result of a competitive fragmentation, producing ethyl 2-methylenebut-3-enoate, which underwent known dimerization through a Diels-Alder reaction. ${ }^{7}$ The presence of carboxylic ester and protected amino groups on the phenols was tolerated well (entries 9 and 10). Intriguingly, a phenol featuring a Boc-protected amino substituent produced a mixture of $E$ and $Z$ isomers (entry 10). Ortho and meta substitutions on the phenol ring were also well tolerated (entries 11-13), although we observed a slight decrease in stereoselectivity in the case of $o$-cresol (entry 12). Extreme steric hindrance around the phenolic nucleophile diminished the reaction efficiency. For instance, 2,6-dimethylphenol provided a relatively low yield (entry 14) and 2,6-di-tert-butylphenol gave no reaction (entry 15).

Further substitution at the $\beta^{\prime}$-position of the allene produced $Z$-olefins, presumably because of steric clash between the methyl and alkyl groups (entries 16-18). Furthermore, the $\beta^{\prime}$ substitution protected the arylallyl ether $\mathbf{1 q}$ from undergoing fragmentation to produce the diene, ${ }^{7}$ providing 1q in $97 \%$ isolated yield (entry 17 ; cf. entry $8,73 \%$ ). Allenonitrile also worked well as the electrophile: the arylallyl ether $1 \mathbf{r}$ was obtained in excellent yield (entry 18). ${ }^{8}$

Because our initial investigations with phenol pronucleophiles were highly successful, we expanded our exploration of the $\beta^{\prime}$-umpolung additions to amine-based pronucleophiles (Table 2). $N$-Phenyl- $p$-toluenesulfonamide gave its expected product in excellent yield, albeit as a 2.5:1 mixture of $E$ and $Z$ olefins (entry 1). $N$-Benzyl-p-toluenesulfonamide and tert-butyl $N$-tosylcarbamate pronucleophiles were also viable substrates (entries 2 and 3). $p$ Toluenesulfonamide itself resulted in lower product yield and selectivity, favoring the $Z$ olefin geometry (entry 4). The use of tert-butyl $\mathrm{N}$-phenylcarbamate resulted in no reaction product, due to the diminished acidity of the pronucleophile (entry 5). ${ }^{3 \mathrm{~g}}$ The allylic amine product derived from phthalimide was obtained in $71 \%$ yield as a single $E$ isomer (entry 6). $p$-Toluenesulfonohydrazine gave its $\beta$-amino acid product in moderate yield (entry 7). $N$ Tosyl-protected ethyl phenylalanine was also a suitable pronucleophile, producing the amide $2 \mathbf{h}$ in excellent yield (entry 8). Employing protected amines provides access to $\alpha$-substituted $\beta$-amino esters, which have great utility in $\beta$-peptide chemistry; ${ }^{9}$ in addition, $\alpha$-Methylene- $\beta$ alanine is a naturally occurring herbicidal amino acid. ${ }^{10}$

Carboxylic acids also turned out to be excellent pronucleophiles for this $\beta^{\prime}$-umpolung reaction and worked well with a variety of diversely substituted allenoates (Table 3 ). With ethyl $\alpha$-methyl allenoate, both acetic acid and benzoic acid provided their corresponding acylated allylic alcohols in excellent yields, as $E$ isomers exclusively (entries 1 and 2). ${ }^{11}$ Complementary to the N-terminus addition of phenylalanine (Table 2, entry 8), the Cterminus addition of $\mathrm{N}$-tert-butoxycarbonyl phenylalanine was just as efficient (Table 3, entry 3). The mild and neutral conditions ensured that no epimerization occurred during the reaction. ${ }^{12}$ Benzoic acid reacted as anticipated with the $\gamma$-methyl-substituted allenoate (entry 4), but the excessively large $\gamma$-tert-butyl substituent inhibited the reaction (entry 5). Ethyl $\alpha$ (5-hexenyl)allenoate was compatible with the transformation (entry 6). In accordance with our observations regarding phenol pronucleophiles, the $\alpha$-benzyl allenoate produced its $Z$ olefin in excellent yield (entry 7). Diethyl 2-vinylidenesuccinate also proved to be a viable substrate for the $\beta^{\prime}$-addition of benzoic acid, producing a mixture of its two olefinic isomers in excellent yield (entry 8).

We further expanded the reaction scope to consider carbon-centered pronucleophiles. The reaction of malononitrile with ethyl $\alpha$-methyl allenoate gave a $Z$-configured olefin product, which structurally resembles a mixed Rauhut-Currier adduct (4, eq 3$)$, in $86 \%$ yield. ${ }^{13}$ Although dimethyl malonate and ethyl cyanoacetate did not undergo corresponding $\beta^{\prime}$ - 
umpolung additions, $\alpha$-alkylcyanoacetates did. ${ }^{14}$ The actual pronucleophiles employed were alkylidenecyanoacetates, which underwent $\gamma$-deprotonation and addition at the $\alpha$-carbon atom (Table 4). We obtained the resulting dienes as mixtures of $E$ and $Z \alpha, \beta$-unsaturated enoates, with the $\beta, \gamma$-olefin unit from the cyanoacetate existing exclusively in $E$ form. Although we obtained these products in relatively modest yields, the alkylcyanoacetate pronucleophiles provided access to highly functionalized all-carbon diene substrates.

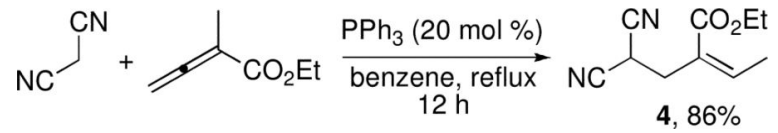

Furfuryl alcohol, oxime, and thiol functionalities were compatible with the $\beta^{\prime}$-umpolung addition (Table 5). While most aliphatic alcohols did not participate in the umpolung reaction, due to their high values of $\mathrm{p} K_{\mathrm{a}},{ }^{15}$ the relatively low $\mathrm{p} K_{\mathrm{a}}$ of furfuryl alcohol (9.55) made it a prime candidate for the $\beta^{\prime}$-addition reaction (entry 1$)$. Oximes and thiols also possess suitable values of $\mathrm{p} K_{\mathrm{a}}$ for this transformation. Indeed, $(E)$-benzaldehyde oxime ( $\mathrm{p} K_{\mathrm{a}}$ 11.3) and benzenethiol ( $\left.\mathrm{p} K_{a} 7\right)$ underwent the reaction smoothly (entries 2 and 3). O-Allyl oximes are useful synthetic precursors for allylation of activated methylene compounds ${ }^{16}$ and [2,3]-sigmatropic N,O rearrangements. ${ }^{17}$ When treated with palladium(II), oxime $O$ allyl ether undergoes formal [2,3]-sigmatropic rearrangement to form $\mathrm{N}$-allyl nitrone, which can then be engaged in a dipolar cycloaddition reaction in situ. ${ }^{18} \mathrm{O}$-Allyl oximes have also been converted in one step into pyrroles under iridium catalysis. ${ }^{19}$

Scheme 2 presents a plausible mechanism for this reaction. Phosphine addition to the allenoate gives the phosphonium dienolate 9 . A well-established equilibrium between the phosphonium enolate $\mathbf{9}$ and the vinylogous phosphorous ylide $\mathbf{1 0}$ is facilitated through proton transfer steps. ${ }^{4 \mathrm{~d}, \mathrm{f}, \mathrm{g}}$ Deprotonation of the pronucleophile by the ylide $\mathbf{1 1}$ forms the phosphonium enoate electrophile 12. Conjugate addition of the anionic nucleophile to the enoate and subsequent $\beta$-elimination of the phosphine yields the observed $\beta^{\prime}$-umpolung addition product.

As mentioned previously, many of these substrates are synthetically useful. For example, we performed a further transformation of the allylphenyl ether 1a. Upon heating in diethylaniline under reflux, the allylaryl ether 1a underwent a facile Claisen rearrangement, lactonization, and isomerization cascade to produce 3,4-dimethylcoumarin (13, eq 4). ${ }^{20}$

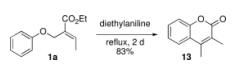

This paper reports the first examples of $\beta^{\prime}$-umpolung additions of nucleophiles (carbon-, oxygen-, nitrogen-, and sulfur-centered) to activated allenes, producing many useful synthetic intermediates in good to excellent yields - often with high levels of selectivity for the olefin geometry. Whereas activated $\alpha$-monosubstituted allenes undergo the wellestablished $\gamma$-umpolung addition, activated $\alpha$-disubstituted allenes undergo $\beta^{\prime}$-umpolung addition exclusively, underlining the synthetic utility of this versatile class of molecules. As a showcase of the power of this reported reaction, we performed a one-step cascade process from an allylphenyl ether intermediate to a coumarin product. We are currently exploring applications of this methodology to other syntheses of small molecules. 


\section{Supplementary Material}

Refer to Web version on PubMed Central for supplementary material.

\section{Acknowledgments}

Financial support was provided by the NIH (R01GM071779 and P41GM081282).

\section{References}

1. For reviews, see: a Lu X, Zhang C, Xu Z. Acc. Chem. Res. 2001; 34:535. [PubMed: 11456471] b Valentine DH, Hillhouse JH. Synthesis. 2003; 3:317. c Methot JL, Roush WR. Adv. Synth. Catal. 2004; 346:1035. d Lu X, Du Y, Lu C. Pure Appl. Chem. 2005; 77:12., 1985. e Nair V, Menon RS, Sreekanth AR, Abhilash N, Biji AT. Acc. Chem. Res. 2006; 39:520. [PubMed: 16906748] f Denmark SE, Beutner GL. Angew. Chem., Int. Ed. 2008; 47:1560. g Ye L, Zhou J, Tang Y. Chem. Soc. Rev. 2008; 37:1140. [PubMed: 18497927] h Kwong CK-W, Fu MY, Lam CS-L, Toy PH. Synthesis. 2008:2307. i Aroyan CE, Dermenci A, Miller SJ. Tetrahedron. 2009; 65:4069. j Cowen BJ, Miller SJ. Chem. Soc. Rev. 2009; 38:3102. [PubMed: 19847345] k Marinetti A, Voituriez A. Synlett. 2010:174. 1 Beata K. Cent. Eur. J. Chem. 2010:1147.

2. a Trost B, Li C-J. J Am. Chem. Soc. 1994; 116:3167. b Trost B, Li C-J. J. Am. Chem. Soc. 1994; 116:10819. c Trost B, Drake G. J. Org. Chem. 1997; 62:5670. Albeit not in catalytic form, Cristau first demonstarted the $\gamma$-umpolung addition of nucleophiles to activated allenes; see: d Cristau H-J, Viala J, Christol H. Tetrahedron Lett. 1982; 23:1569. e Cristau H-J, Viala J, Christol H. Bull. Chim. Soc. Fr. 1985; 5:980. f Cristau HJ, Fonte M, Torreilles E. Synthesis. 1989:301.

3. a Lu X, Zhang C. Synlett. 1995:645.b Chen Z, Zhu G, Jiang Q, Xiao D, Cao P, Zhang X. J. Org. Chem. 1998; 63:5631.c Alvarez-Iberra C, Csaky A, Olivia CG. Tetrahedron Lett. 1999; 40:8465.d Alvarez-Iberra C, Csaky A, Gomez de la Olivia C. J. Org. Chem. 2000; 65:3544. [PubMed: 10843645] e Lu C, Lu X. Org. Lett. 2002; 4:4677. [PubMed: 12489959] f Pakulski Z, Demchuk OM, Frelek J, Luboradzki R, Pietrusiewicz KM. Eur. J. Org. Chem. 2004:3913.g Virieux D, Guillouzic A-F, Cristau H-J. Tetrahedron. 2006; 62:3710.h Chung YK, Fu GC. Angew. Chem., Int. Ed. 2009; 48:2225.i Smith SW, Fu GC. J. Am. Chem. Soc. 2009; 131:14231. [PubMed: 19772285] j Guan X-Y, Wei Y, Shi M. Org. Lett. 2010; 12:5024. [PubMed: 20936863] k Zhang Q, Yang L, Tong X. J. Am. Chem. Soc. 2010; 132:2550. [PubMed: 20131904]

4. a Zhu X-F, Lan J, Kwon O. J. Am. Chem. Soc. 2003; 125:4716. [PubMed: 12696883] b Tran Y, Kwon O. Org. Lett. 2005; 7:4289. [PubMed: 16146409] c Castellano S, Fiji HDG, Kinderman SS, Watanabe M, De Leon P, Tamanoi F, Kwon O. J. Am. Chem. Soc. 2007; 129:5843. [PubMed: 17439124] d Tran Y, Kwon. J. Am. Chem. Soc. 2007; 129:12632. [PubMed: 17914823] e Lu K, Kwon O. Org. Synth. 2009; 86:212. [PubMed: 20161208] f Guo H, Xu Q, Kwon O. J. Am. Chem. Soc. 2009; 131:6318. [PubMed: 19374356] g Khong SN, Tran YS, Kwon O. Tetrahedron. 2010; 66:4760. [PubMed: 21359169]

5. a Zhao G-L, Shi M. Org. Biomol. Chem. 2005; 3:3686. [PubMed: 16211103] b Wurz RP, Fu GC. J. Am. Chem. Soc. 2005; 127:12234. [PubMed: 16131196] c Wang T, Ye S. Org. Lett. 2010; 12:4168. [PubMed: 20712333]

6. Drewes SE, Emslie ND, Karodia N, Loizou G. Synth. Commun. 1990; 20:1437.

7. Mandai T, Yokoyama H, Miki T, Fukuda H, Kobata H, Kawada M, Otera J. For entry 8, the DielsAlder adduct was isolated in $25 \%$ yield. For other entries, this adduct was observed in the ${ }^{1} \mathrm{H}$ NMR spectra of the crude products. The characteristics of the isolated adduct matched those reported in the literature; see. Chem. Lett. 1980:1057.

8. Compound 1r contains the phenoxy phenyl propylamine skeleton found in a number of pharmaceuticals (e.g., the antidepressant fluoxetine); see: a Wong D, Horng J, Bymaster F, Hauser K, Molloy B. Life Sciences. 1974; 15:471. [PubMed: 4549929] b Wong D, Perry K, Bymaster F. Nature Rev. 2005; 4:764.

9. For reviews, see: a Seebach D, Matthews JL. J. Chem. Soc., Chem. Commun. 1997; 21:2015. b Lelais G, Seebach D. Biopolymers. 2004; 76:206. [PubMed: 15148683] c Seebach D, Beck AK, Bierbaum DJ. J. Chem. Biodiversity. 2004; 1:1111. 
10. Isaac BG, Ayer SW, Stonard RJ. J. Antibiot. 1991; 44:7, 795.

11. (E)-Ethyl 2-acetoxy-2-butenoate (3a) is an intermediate for the synthesis of mikanecic acid; see: Edwards JD, Matsumoto T, Hase T. J. Org. Chem. 1967; 32:244.

12. No epimerization occurred during the reaction, as verified through HPLC analysis; see the Supporting Information for details.

13. Aroyan C, Dermenci A, Miller S. Tetrahedron. 2009; 65:4096.

14. Lu has reported that tributylphosphine facilitates $\gamma$-umpolung addition of dimethyl malonate to ethyl $\alpha$-methyl allenoate; see ref. 3 a.

15. Lu has reported that benzyl alcohol functions as a $\gamma$-umpolung donor when reacted with allenoates; see ref. 3a.

16. Suzuki O, Hashiguchi Y, Inoue S, Sato K. Chem. Lett. 1988:291.

17. Davies S, Fox J, Jones S, Price A, Sanz M, Seller T, Smith A, Teixeira F. J. Chem. Soc., Perkin Trans. 1. 2002:1757.

18. Oikawa M, Takeda Y, Naito S, Hashizume D, Koshino H, Sasaki M. Tetrahedron Lett. 2007; 48:4255.

19. Wang H-Y, Mueller D, Sachwani. Londino H, Anderson L. Org Lett. 2010; 12:2290. [PubMed: 20411970]

20. For the synthesis of 3,4-dimethylcoumarin, see: a Dittmer DC, Li Q, Avilov DV. J. Org. Chem. 2005; 70:4682. [PubMed: 15932305] b Chatterjee AK, Toste FD, Goldberg SD, Grubbs RH. Pure Appl. Chem. 2003; 75:421. c Fuerstner A, Jumbam DN, Shi N. Z. Naturforsch., B: Chem. Sci. 1995; 50:326. d Patil VO, Kelkar SL, Wadia MS. Indian J. Chem., Sect. B. 1987; 26B:674. e Mali RS, Tilve SG, Patil KS, Nagarajan G. Indian J. Chem., Sect. B. 1985; 24B:1271. f Falsone G, Spur B, Wingen HP. Arch. Pharm. 1983; 316:763. g Motoyoshiya J, Teranishi A, Mikoshiba R, Yamamoto I, Gotoh H. J. Org. Chem. 1980; 45:5385. 


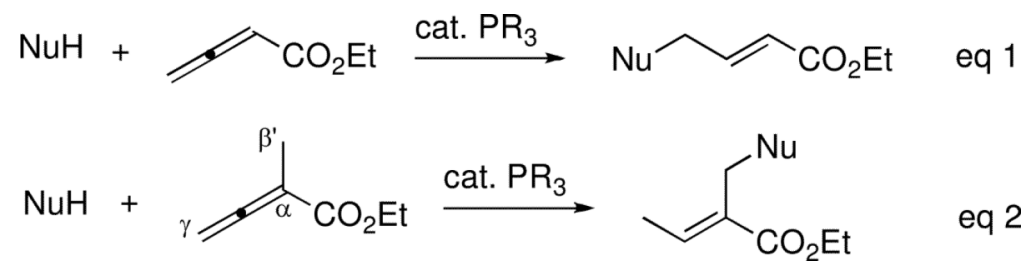

Scheme 1.

$\gamma$-Addition and $\beta^{\prime}$-Umpolung Addition of Allenes 


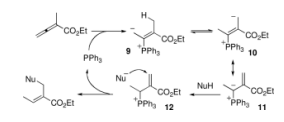

Scheme 2.

Mechanism of the $\beta^{\prime}$-Umpolung Addition 


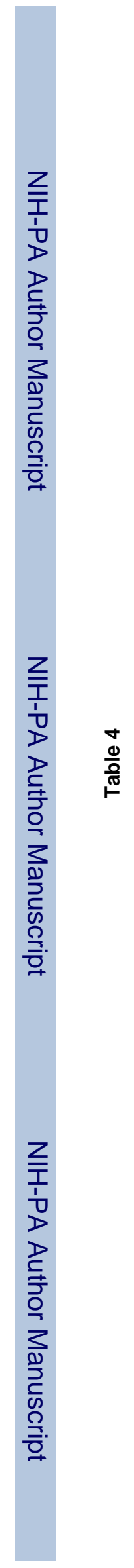

Martin et al.

Page 11

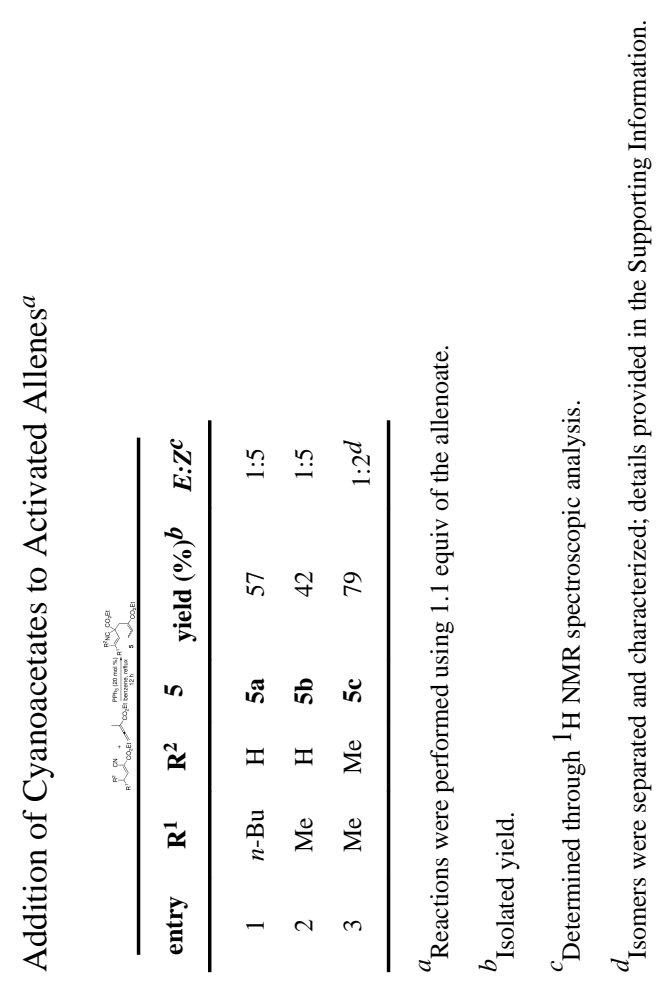

Org Lett. Author manuscript; available in PMC 2012 May 20. 
Table 5

Addition of Pronucleophiles to Ethyl $\alpha$-Methylallenoate ${ }^{a}$

\begin{tabular}{ccccc}
\multicolumn{5}{c}{} \\
\hline entry & NuH & yield $(\%)$ & product & $\boldsymbol{E} / \boldsymbol{Z}^{\boldsymbol{c}}$ \\
\hline 1 & furfuryl alcohol & 88 & $\mathbf{6}$ & $1: 1$ \\
2 & $(E)$-benzaldehyde oxime & 77 & $\mathbf{7}$ & $4: 1$ \\
3 & $\mathrm{PhSH}$ & 65 & $\mathbf{8}$ & $5: 1$ \\
\hline
\end{tabular}

${ }^{a}$ Reactions were performed using 1.1 equiv of allenoate.

$b_{\text {Isolated yield. }}$

${ }^{c}$ Determined through ${ }^{1} \mathrm{H}$ NMR spectroscopic analysis. 